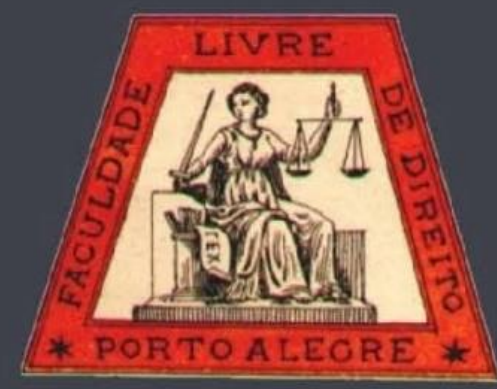

\title{
Parcerias público-privadas: amplitude da capacidade institucional em prestação de serviços públicos"
}

Public-private partnerships:breadth of institutional capacity in providing public services"

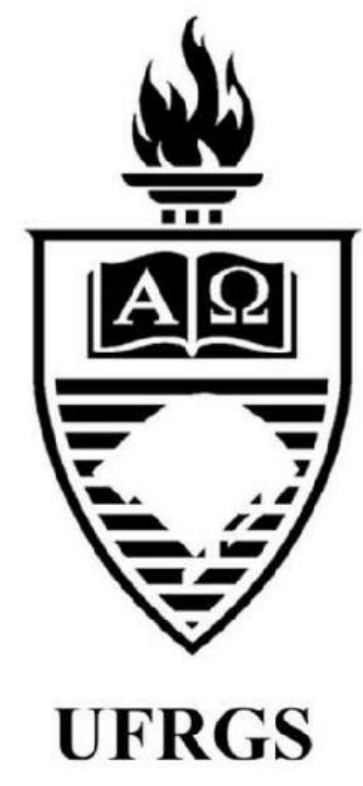

Maria Marconiete Fernandes Pereira Centro Universitário de João Pessoa 


\title{
Parcerias público-privadas: amplitude da capacidade institucional em prestação de serviços públicos
}

\author{
Public-private partnerships: breadth of institutional capacity in providing public services
}

\author{
Maria Marconiete Fernandes Pereira*
}

\begin{abstract}
REFERÊNCIA
PEREIRA, Maria Marconiete Fernandes. Parcerias público-privadas: amplitude da capacidade institucional em prestação de serviços públicos. Revista da Faculdade de Direito da UFRGS, Porto Alegre, n. 36, p. 246-264, ago. 2017.
\end{abstract}

\begin{abstract}
RESUMO
O trabalho mostra a inter-relação do uso da expressão "parcerias" no contexto de concessões administrativas e patrocinadas, significando a colaboração estabelecida entre o setor público e o privado. O instituto jurídico das concessões renova-se com a criação do sistema de Parceria Público-Privada. Tem como objetivo a execução de obras, a elaboração de projetos, financiamentos, gestão, operações e manutenção de serviços públicos. Busca-se com ele melhorar a prestação dos serviços em termos de eficiência e de resultados. Essa espécie de parceira é analisada neste artigo com base nas modalidades de concessões patrocinadas e administrativas, sua aplicabilidade em consonância com as diretrizes institucionais, bem como a importância do procedimento licitatório. $\mathrm{O}$ modelo teórico proposto sugere que a adoção das parcerias público-privadas poderá ser uma das vias institucionais para a melhoria da capacidade na prestação de serviços públicos.
\end{abstract}

\section{PALAVRAS-CHAVE}

Parcerias público-privadas. Concessão. Serviços públicos.

\section{ABSTRACT}

This paper shows the term "partnerships" use on administrative and sponsored concessions meaning the collaboration established between public and private sectors. The legal concessions are renewed with PublicPrivate Partnership rules. The objective of this paper is to analyze execution of works, elaboration of projects, financing, management, operations and maintenance of public services. It is intended find ways to improve the service success in terms of efficiency and better results. Partnership is analyzed based on modalities of sponsored and administrative concessions, their applicability according to institutional guidelines and the importance of bidding procedure. The theoretical model proposed suggests that the adoption of Public-Private Partnerships could be one institutional way to improve the capacity to provide public services.

\section{KEYWORDS}

Public-private partnerships. Concession. Public services.

\section{SUMÁRIO}

Introdução. 1. Contextualização das parcerias público-privadas. 1.1. Concessão patrocinada. 1.2. Concessão administrativa. 2. Diretrizes institucionais das PPP. 2.1. Eficiência. 2.2. Responsabilidade fiscal e transparência. 2.3. Repartição objetiva de riscos. 2.4. Sustentabilidade. 3. Procedimento licitatório. 3.1. Fase interna. 3.2. Fase externa. Conclusão. Referências.

\section{INTRODUÇÃO}

O impacto da nova ordem mundial, influenciada pela globalização, refletiu no percurso histórico do modelo do Estado brasileiro, financiador e empresário. Pode ser analisado como ponto de inflexão em face da retração na capacidade de financiamento em obras de infraestrutura e de prestação de serviços públicos. Esses condicionamentos foram

\footnotetext{
* Professora Titular de Direito Tributário do Centro Universitário de João Pessoa (UNIPÊ). Doutora em Direito Público (Universidade Federal de Pernambuco - UFPE, 2015). Mestre em Ciências Jurídicas (Universidade Federal de Paraíba UFPB, 2009). Especialista em Contabilidade e Auditoria Pública (UFPB, 1998). Graduada em Direito (UNIPÊ, 2005), Ciências Contábeis (UFPE, 1990) e Licenciatura em Ciências (Faculdade de Formação de Professores de Petrolina, 1983). Auditora de Contas Públicas na Controladoria Geral do Estado da Paraíba.
} 
determinantes na implementação de reformas econômicas, destacando-se a liberalização comercial, a qual provoca a redução das tarifas de importações, além da privatização.

As reformas promovidas tinham como lastro ideológico as concepções e proposições sugeridas pelo Consenso de Washington, que enfatizava a necessidade de um profundo ajuste estrutural do Estado, restabelecendo o crescimento econômico ${ }^{1}$ com propostas de liberalização do sistema. ${ }^{2}$ Havia um entendimento convergente entre economistas e líderes políticos democráticos sobre a importância do mercado. Defendia-se que fossem estabelecidas e amplamente adotadas as new rules of the game, como instrumento de retomada do crescimento econômico. ${ }^{3}$

Em razão de políticas elaboradas com a finalidade de dar-se plena autonomia às forças de mercado, o conjunto de ações reformistas passou a ser conhecido como neoliberalismo. ${ }^{4}$ Tais diretrizes "provocaram críticas, demonizando o Estado, ao invés de se concentrarem nas mudanças institucionais que iriam melhorar seu desempenho". ${ }^{5}$ Essa política ideológica levou a uma orientação interdisciplinar entre o direito e a economia. Esse inter-relacionamento gerou duas percepções: a intervenção do Estado na economia e a participação do setor privado nas atividades econômicas públicas.

\footnotetext{
1 UGÁ, Maria Alícia Dominguez. Ajuste estrutural, governabilidade e democracia. In: GERSCHMAN, Silvia; VIANNA, Maria Lucia Werneck. A miragem da pósmodernidade e políticas sociais no contexto da globalização. Rio de Janeiro: Fiocruz, 1997.

2 DINIZ, Eli. O pós-Consenso de Washington: globalização, Estado e governabilidade reexaminados. In (Org.). Globalização, Estado e desenvolvimento: dilemas do Brasil no novo milênio. Rio de Janeiro: FGV, 2007.

3 CAVAllo, Domingo. Latin America and The Washington Consensus. Harvard University Economics Department. Spring, 2004. Disponível em: <http://www.cavallo.com.ar/wpcontent/uploads/2011/08/LA-and-the-WashingtonConsensus.pdf >. Acesso em: 22 abr. 2017.
}

O processo de surgimento de novos contornos da gestão pública e dos papéis do Estado na sociedade contemporânea evidenciou a falência do modelo de Estado do bem-estar social. Esse modelo tinha como característica basilar a intensa influência da intervenção do Estado nas atividades econômicas, por meio de políticas e programas desenvolvimentistas. $6 \quad$ Em consequência, essa nova visão de gestão pública exigiu adaptações, transformações e reformulações nas funções do Estado. Este deixaria de ser ator único para ser partícipe, inserido num processo de gestão de políticas públicas de fomento e de delegação de serviços públicos.

A pergunta que este artigo se propõe responder é: O modelo legislativo brasileiro que estabeleceu parcerias entre os setores público e privado é capaz de assegurar a ampliação da prestação de serviços públicos? Importa enfatizar que há um duplo desafio: diminuir o tamanho do Estado e melhorar o desempenho da prestação dos serviços públicos. ${ }^{7}$ Trata-se de uma tarefa difícil de se enfrentar, diante dos processos de inovação de gestão. Uma das alternativas seria a crença no potencial do mercado, impulsionador de uma gestão mais eficiente a cargo do setor privado. Esse modelo de gestão legitimaria o estabelecimento de parcerias, por meio da

${ }^{4}$ DANTAS, Ivo. Teoria do Estado contemporâneo. Rio de Janeiro: Forense, 2008.

${ }^{5}$ EVANS, Peter B. Análise do Estado no mundo neoliberal: uma abordagem institucional comparativa. Revista de Economia Contemporânea, Rio de Janeiro, n. 4, jul./dez. 1998.

6 OLIVEIRA, Gustavo Henrique Justino de. Estado contratual, direito ao desenvolvimento e parceria públicoprivada. In: TALAMINI, Eduardo; JUSTEN, Monica Spezia (Org.). Parcerias público-privadas: um enfoque multidisciplinar. São Paulo: Revista dos Tribunais, 2005.

${ }^{7}$ KETTL, Donald F. Global reinvention: basic issues, questions ahead. Forum on Reinventing Government. Jan. 1999. Disponível em:

<http://www.brookings.edu/research/papers/1999/01/14go vernance-kettl>. Acesso em: 26 jul. 2016. 
delegação integral ou parcial de prestação de serviços públicos.

A lógica de funcionamento do mercado no âmbito, atividades econômicas de serviços públicos, permitiu que a iniciativa privada participasse desse novo ambiente público. Sua implementação requer a liberação de recursos financeiros por instituições de fomento, necessários aos investimentos para empreendimentos, principalmente, de infraestrutura. As variadas formas de delegação de prestação de serviços públicos possibilitariam um modelo de gestão de negócios públicos a partir das concessões de serviços públicos.

Na década de oitenta do século passado, as ideologias voltadas à defesa da economia de mercado transformaram-se em tendência mundial. No Brasil, iniciaram-se as reformas constitucionais e a participação da iniciativa privada no processo de delegação de serviços públicos. Medidas de reformas econômicas dirigidas ao mercado foram implementadas, tais como: a privatização, a liberalização comercial acompanhada de uma ampla diminuição das tarifas de importações e o ajustamento fiscal.

Posteriormente, as diversas transformações, no contexto brasileiro, foram concretizadas pela implantação do Plano Real, em 1994. Essas transformações permitiram a estabilização da moeda e o controle da inflação, associadas à premissa de reduzir os custos do setor público. Entretanto, a retomada de investimentos somente foi possível após um período de ajustes das atividades econômicas no país, já que esse resultado não ocorre de forma automática. ${ }^{8}$ À

8 SCHIMIDT-HEBBEL, Klaus; SERVÉN, Luís; SOLIMANO, Andrés. Saving investment: paradigmas, puzzles, policies. The World Bank Research Observer, v. 11, n. 1, fev. 1996.

${ }^{9}$ RIGOLON, Francisco José Zagari; PICCININI, Maurício Serrão. O investimento em infraestrutura e a retomada do crescimento econômico sustentado. Textos para Discussão do BNDES, Texto para Discussão $\mathrm{n}^{\circ}$ 63, Rio de Janeiro, IPEA, dez. 1997. Disponível em: <http://www.bndes.gov.br/SiteBNDES/export/sites/default época, vivia-se um período de grande instabilidade econômica e política.

Identificam-se duas questões relevantes nesse processo, na busca de resolução da problemática proposta: a) a importância do setor privado na economia e sua atuação na prestação dos serviços públicos; b) o início de uma nova fase de relação entre o público e o privado. Transcreve-se, em relação à crise das finanças no Brasil, a seguinte afirmativa:

Uma das consequências visíveis da crise das finanças públicas no Brasil, ao longo das décadas de 80 e 90 , foi a progressiva perda da capacidade de o Estado alocar recursos na expansão e manutenção da infraestrutura. O resultado desse processo foi uma crescente deterioração da qualidade desses serviços, com impactos indesejáveis na produtividade do sistema econômico e na competitividade dos produtos brasileiros. ${ }^{9}$

Segundo diagnóstico do Banco Mundial ${ }^{10}$, um dos caminhos para alcançar o desenvolvimento é suprir as necessidades de serviços em infraestrutura, através de parceria entre o poder público e a iniciativa privada, na busca de prestação de serviços eficientes. O investimento em infraestrutura está diretamente ligado ao desempenho econômico de um país ou região. Idêntica relação ocorre para a melhoria na qualidade de vida, destacando-se, principalmente, a saúde e a educação. Nesse aspecto, o impacto dos projetos de infraestrutura relaciona-se com crescimento econômico e distribuição de renda. Inversamente, essa relação resulta em insuficiência ou deficiência em ativos de infraestrutura que interferem no desenvolvimento econômico de um país. ${ }^{11}$

/bndes_pt/Galerias/Arquivos/conhecimento/td/Td-63.pdf>. Acesso em: 28 jun. 2016.

10 WORLD BANK. World Development Report 1994: infrastructure for development (Executive Summary). Washington, DC, 1994. Disponível em: <http://wwwwds.worldbank.org/external/default/WDSContentServer/I W3P/IB/2007/10/10/000011823_20071010172019/Render ed/PDF/13483.pdf >. Acesso em: 30 jun. 2016.

${ }^{11}$ CALDERÓN, César; SERVÉN, Luis. The effects of infrastructure development on growth and income 
As justificativas apresentadas pelos governos para atender às demandas em infraestrutura foram: a) a expertise da iniciativa privada na gestão de atividades públicas; b) a liberação orçamentária de investimentos para outros fins; c) o controle fiscal. Havia a presunção de que o Estado, em seu papel de executor de bens e serviços, não teria como garantir a qualidade desse serviço. Dito de outra forma, a incapacidade do Estado poderia ser suprida pela iniciativa privada com menores custos e maior eficiência.

A iniciativa privada ganhou proteção constitucional como princípio fundamental na ordem econômica. Com esse respaldo, passou a papel determinante na exploração da atividade econômica, substituindo o setor público. Ao Estado cabe, prioritariamente, defender os imperativos da segurança nacional e assegurar os relevantes serviços de interesse coletivo, conforme definidos em lei e como pressupostos da caracterização do sistema econômico.

Com efeito, o regime de exploração dos serviços públicos passou por uma considerável reestruturação. Foram introduzidos, no sistema brasileiro, serviços sujeitos à regulação, exigindo a devida colaboração entre o setor público e o privado. Essa colaboração iniciou-se com a instituição das Leis de Concessões e Permissões (Leis nº 8.987, de 13/02/95, e n ${ }^{\circ} 9.074$, de 7/7/95). Esses dois diplomas legais provocaram alterações substanciais na exploração concorrencial dos serviços públicos comerciais e industriais. No entanto, essas alterações não foram suficientes para suprir a carência na prestação de serviços e na flexibilidade de gestão. $\mathrm{O}$ aumento do investimento privado em setores de atividades produtivas fez parte de um contexto de revisão dos pressupostos do Estado gestor em seus compromissos financeiros. Diante disso, novas oportunidades surgiram para a atuação do setor privado na oferta de serviços de infraestrutura nas áreas estratégicas de desenvolvimento.

O regime de parceria, para fins de prestação de serviços no setor público, pela iniciativa privada, com investimentos e infraestrutura, consolidou-se, no ordenamento brasileiro, com o advento da Lei $\mathrm{n}^{\circ} 11.079$, de 24 de dezembro de 2004. Essa lei regulamentou os contratos de concessão administrativa e patrocinada, estabelecendo normas gerais sobre parceria público- privada, no âmbito da administração pública direta. Abrangeu também os fundos especiais, as autarquias, as fundações públicas, as empresas públicas, as sociedades de economia mista e as demais entidades controladas, direta ou indiretamente, pela União, Estados, Distrito Federal e Municípios. Além disso, acrescentou novas regras à Lei de Concessão Comum (Lei ${ }^{\circ}$ 8.987, de 13 de fevereiro de 1995), e à Lei de Licitações e Contratos Administrativos (Lei ${ }^{\circ}$ 8.666, de 21 de junho de 1993).

Este trabalho pretende analisar a moldura contextual brasileira em relação às parcerias público-privadas. Aborda as tipologias das concessões patrocinadas e administrativas, demonstrando que a contraprestação pecuniária pode ser definida a partir do perfil do usuário do serviço. Nessa linha, é importante analisar as diretrizes institucionalizadas para as concessões, em termos de viabilização de resultados na prestação dos serviços, com a perspectiva de segurança funcional do empreendimento. Convém frisar que a execução das diretrizes decorre do êxito do procedimento licitatório, em suas fases interna e externa, que trouxe estrutura específica ao processo. Para que se possa atingir tal desiderato, a iniciativa privada e o poder estatal formam parcerias a partir de concessões para exploração de serviços públicos.

distribution. In: Reunión Latinoamericana sobre el Financiamiento de la Infraestructure, April 15-16, 2004, Buenos Aires. Publications... Washington, DC: WBG. 


\section{CONTEXTUALIZAÇÃO DAS PARCERIAS PÚBLICO-PRIVADAS}

A Constituição Federal de 1988 reservou ao regime da concessão a exploração da prestação de serviços públicos pelo ente estatal ou pela iniciativa privada, por meio de uma lei que defina os pilares fundamentais do instituto. Nesse sentido, estabelece o parágrafo único do art. 175:

Parágrafo único. A lei disporá sobre:
I - o regime das empresas concessionárias
permissionárias de serviços públicos, o caráter
especial de seu contrato e de sua prorrogação, bem
como as condições de caducidade, fiscalização
rescisão da concessão ou permissão;
II - os direitos dos usuários;
III - política tarifária;
IV - a obrigação de manter serviço adequado. ${ }^{12}$

Entretanto, a Constituição não estabelece, dentro do sistema organizativo, um único modelo de concessão, indicando apenas delineamentos mínimos na configuração da concessão de serviços públicos à iniciativa privada. Evidentemente, o contrato administrativo tem o objetivo de disciplinar a concessão de serviços específicos para os diversos tipos ensejadores da configuração concessionária. No âmbito do ordenamento brasileiro, existem as seguintes espécies de concessão ${ }^{13}$ :

- Concessão comum de serviço público (Lei $\mathrm{n}^{\circ}$ 8.987, de 13 de fevereiro de 1995);

- Concessão de serviço público precedida da execução de obra pública (Lei $\mathrm{n}^{\circ}$ 8.987, de 13 de fevereiro de 1995);

- Concessão patrocinada de obras públicas (Lei $\mathrm{n}^{\mathrm{o}}$ 11.079, de 30 de dezembro de 2004);

\footnotetext{
${ }^{12}$ BRASIL. Constituição da República Federativa do Brasil de 1988. Diário Oficial da União, Brasília, 5 de outubro de 1988. Disponível

<http://www.planalto.gov.br/ccivil 03/constituicao/constit uicaocompilado.htm>. Acesso em: 22 jun. 2016.
}

- Concessão patrocinada de serviços públicos (Lei $\mathrm{n}^{\mathrm{o}}$ 11.079, de 30 de dezembro de 2004);

- Concessão administrativa de prestação de serviços (Lei $n^{\circ} 11.079$, de 30 de dezembro de 2004);

- Concessão de uso de bem público, com ou sem exploração do bem (disciplinada por legislação esparsa). ${ }^{14}$

O regramento constitucional estabelece que, entre as espécies de concessão, existe a necessidade de se fazer procedimento licitatório na modalidade de concorrência, justificando-se a conveniência da outorga, a especificação do objeto, área e prazo. A exigência de licitação é respaldada em princípios que garantem e asseguram isonomia entre os concorrentes, visando à proposta mais vantajosa para a administração pública e a promoção do desenvolvimento sustentável. Além disso, são observados os princípios da legalidade, impessoalidade, moralidade, igualdade, publicidade e probidade administrativa, entre outros. Diante da imperatividade constitucional da licitação, afasta-se a concessão com base em privilégios no julgamento das propostas dos licitantes.

Os serviços executados por meio de parcerias público-privadas repercutem no cotidiano dos cidadãos, independentemente de que o órgão executor seja pessoa física ou jurídica. Essas parcerias envolvem a concessão de portos e aeroportos; serviços de atendimento à saúde, por meio de hospitais; acesso à educação, por meio de escolas; rodovias para alavancar as entradas e saídas de bens, serviços e produtos, bem como serviços de interesse da população. Há uma relação direta entre o fornecimento de

${ }^{13}$ As concessões objeto de parcerias público-privadas serão estudadas em tópicos específicos.

14 DI PIETRO, Maria Sylvia Zanella. Parcerias na administração pública: concessão, permissão, franquia, terceirização, parceria público-privada e outras formas. 9. ed. São Paulo: Atlas, 2012. 
serviços de alta complexidade e de qualidade aos cidadãos ou consumidores e a garantia de uma melhor aplicação de recursos e gestão de serviços públicos. Essa interação entre o setor público e o privado, estabelecida em contratos de parcerias, representa um importante reforço para a administração pública. A Lei no 11.079, de 30 de dezembro de 2004, estabelece alternativas institucionais quanto aos tipos contratuais, destacando-se duas modalidades:

Concessão patrocinada: é a concessão de serviços públicos ou de obras públicas de que trata a Lei $\mathrm{n}^{\circ} 8.987$, de 13 de fevereiro de 1995, quando envolver, adicionalmente, à tarifa cobrada dos usuários contraprestação pecuniária do parceiro público ao parceiro privado;

Concessão Administrativa: é o contrato de prestação de serviços de que a Administração Pública seja a usuária, direta ou indireta, ainda que envolva execução de obra ou fornecimento e instalação de bens. $^{15}$

A celebração dos contratos de concessão patrocinada e administrativa de parceria públicoprivada confere cláusulas de relacionamento entre a administração pública e a iniciativa privada. Realiza-se através de negócios jurídicos para a exploração empresarial de serviços públicos, limitados a valores contratuais não inferiores a vinte milhões de reais, cujo prazo contratual seja situado entre cinco e trinta e cinco anos.

A relação jurídica público-privada no estabelecimento dessas concessões tem como pressuposto um processo democrático contratual, que orienta a colaboração em nome de interesses públicos. A moldura concessionária concebe à iniciativa privada a capacidade de investimentos iniciais, sem a participação direta da administração pública. Em contrapartida, os

\footnotetext{
${ }^{15}$ BRASIL. Lei $\mathrm{n}^{\mathrm{o}}$ 11.079, de 30 de dezembro de 2004. Institui normas gerais para licitação e contratação de parceria público-privada no âmbito da administração pública. Diário Oficial da União. Brasília, 30 de dezembro de 2004. Disponível em: <http://www.planalto.gov.br/ccivil_03/_ato2004-

2006/2004/lei/111079.htm>. Acesso em: 24 jun. 2016;
}

recursos dos investidores são, geralmente, provenientes de instituições públicas de fomento, principalmente, do BNDES.

$O$ relacionamento entre a administração pública e o setor empresarial evoluiu a partir do reconhecimento de direitos, obrigações, repartição de riscos no empreendimento, garantias contratuais entre as partes etc. Esses elementos permitiram a criação de um novo contexto jurídico. Anteriormente, o poder estatal, em nome de suas prerrogativas, nem sempre conferia segurança jurídica aos investidores, no caso de concessões. Atualmente, há uma política de estímulo à implementação das parcerias público-privadas. No entanto, cabe destacar que os novos modelos de colaboração visam a obter o melhor resultado para os dois setores, assegurando-se o interesse do poder público e o fortalecimento da empresa privada.

A colaboração entre os setores público e privado deve agregar benefícios que justifiquem a participação da iniciativa privada. Porém, o aspecto econômico não deve ser o único critério a ser avaliado para se autorizar a participação da iniciativa privada na implementação de parcerias público-privadas. Outros critérios devem ser considerados para fins dessa concessão. Um deles é a concretização da missão do Estado em atender às demandas da sociedade, de maneira a promover o acesso aos serviços públicos de forma igualitária e economicamente viável.

A legislação referente à parceria públicoprivada patrocinada e administrativa teve o cuidado de definir as hipóteses que não poderão se enquadrar nesse tipo de concessão, destacandose as seguintes: limitação das ações dos gestores, quando o valor do contrato for inferior a $\mathrm{R} \$$

BRASIL. Lei $n^{\circ} 8.987$, de 13 de fevereiro de 1995. Dispõe sobre o regime de concessão e permissão da prestação de serviços públicos, previsto no art. 175 da Constituição Federal e dá outras providências. Diário Oficial da União. Brasília, 13 de fevereiro de 1995. Disponível em: <http://www.planalto.gov.br/ccivil_03/leis/18987cons.htm $>$. Acesso em: 22 jun. 2016. 
20.000.000,00 (vinte milhões de reais); exigência de que a prestação do serviço não seja inferior a cinco anos, tendo por objeto único o fornecimento de mão de obra; fornecimento e instalação de equipamentos ou a execução de obra pública.

\subsection{Concessão patrocinada}

A modalidade de concessão de parceria público-privada patrocinada tem por base um contrato administrativo que envolve uma contraprestação pecuniária advinda de uma estipulação tarifária pela prestação de serviços ou execução de obras, podendo ser total ou parcial. Tem também como objeto a conservação, manutenção, ampliação ou melhoramento de quaisquer obras de interesse público, também com estipulação tarifária, podendo haver, adicionalmente, a contraprestação do parceiro público ao parceiro privado.

A concessão patrocinada tem como objeto, para fins de licitação, a concessão de serviço público vinculada à prestação de serviços ou à execução de obra pública. A identificação caracterizadora de parceria público-privada exige o envolvimento da contraprestação pecuniária do parceiro público ao parceiro privado. Existe também a alternativa institucional tarifária de cobrança diretamente dos usuários dos serviços. Apesar de envolver a concessão de serviços públicos, prevista na Lei $\mathrm{n}^{\circ}$ 8.987/95 (concessão comum), a diferença reside na configuração do enquadramento legislativo. Nesse tipo de contrato, não há a contraprestação pecuniária do parceiro público ao parceiro privado.

O contrato de concessão patrocinada poderá prever: a) gerenciamento da concessão de serviço público pelo parceiro privado; b) cobrança de tarifa dos usuários; c) contraprestação pecuniária do parceiro público ao parceiro privado; d) concessão de obra pública, com posterior gerenciamento da concessão de serviço público. ${ }^{16}$

A concessão patrocinada difere da concessão comum em alguns aspectos, destacando-se os seguintes:

- Contraprestação, que pode ser cobrada do parceiro público ao parceiro privado;

- Lapso temporal mínimo, de cinco anos para implementação de uma PPP;

- Repartição dos riscos e ganhos entre as partes;

- Instituição da sociedade de propósitos específicos (SPE), para fins de assegurar a continuidade da prestação dos serviços.

\subsection{Concessão administrativa}

$\mathrm{O}$ ato de concessão da parceria públicoprivada administrativa toma por base um contrato de prestação de serviços em que a administração pública seja usuária direta ou indireta, ainda que envolva execução de obra ou fornecimento e instalação. Nessa espécie de contrato, são aplicadas, adicionalmente, a Lei ${ }^{\circ} 8.987 / 95$ e a Lei $n^{\circ} 9.074 / 95$, desde que a contraprestação não configure a participação do usuário-cidadão. Em tal modalidade, o parceiro público assume a responsabilidade de assegurar o pagamento dos serviços, independentemente de quem os utiliza. Justifica-se, dessa forma, o objeto do empreendimento que, geralmente, não é autossustentável do ponto de vista de investimentos com retornos financeiros da exploração por tarifas.

A figura do usuário representa uma inovação na modalidade de concessão administrativa. Essa inovação configura uma característica até então exclusiva dos particulares quanto da utilização do serviço. No entanto, a própria administração pública passa a ser a
16 PEREIRA, Maria Marconiete Fernandes. Parceria público-privada: a superação da dicotomia público-privado na relação contratual, quando da repartição do risco e da conformação da responsabilidade fiscal. 2009. $167 \mathrm{f}$. Dissertação (Mestrado em Ciências Jurídicas)Universidade Federal da Paraíba, João Pessoa, 2009. 
usuária e, ao mesmo tempo, concedente, estabelecendo-se a seguinte relação: a) concedente equivalente ao poder público; b) usuário direto e usuária indireta, ou seja, a administração pública, na medida em que disponibilizará o reembolso contraprestacional.

O desdobramento dessa relação precisa ser pontuado com a inovação da inserção do instituto jurídico reformulado do tipo contratual no direito administrativo brasileiro. Esse modelo caracteriza os contratos administrativos de serviços comuns, regidos pela Lei n ${ }^{\circ} 8.666$, de 21 de junho de 1993. Nessa espécie de contrato, é preciso considerar alguns aspectos dos contratos administrativos, tais como:

a) Finalidade mediata em atender às necessidades operacionais da administração pública. Portanto, a atividade deve ser destinada a obter determinado serviço de interesse da administração pública. Já a concessão administrativa tem como escopo mediato a prestação de serviços para prover uma necessidade pública, ainda que envolva a execução de obra ou fornecimento e instalação de bens.

b) Prazo de execução limitado a sessenta meses. Excepcionalmente, esse prazo poderá ser prorrogado por até doze meses, desde que seja justificado. Por sua vez, a concessão administrativa tem seu prazo de execução previsto no próprio instrumento contratual, permitindo que o parceiro privado execute as obrigações convencionadas. No entanto, o prazo não pode ser inferior a cinco anos.

c) Despesa com a execução limitada aos respectivos créditos orçamentários, com a indicação dos recursos previstos no orçamento público, exigindo-se, consequentemente, a reserva orçamentária vinculativa. Logo, a concessão administrativa exige a indicação dos recursos orçamentários, sem a reserva orçamentária imediata. Tais despesas afetarão os exercícios seguintes, conforme determina a Lei de Responsabilidade Fiscal, tendo em vista que a disponibilidade orçamentária deve ocorrer após a prestação do serviço.

\section{DIRETRIZES INSTITUCIONAIS DAS PPP}

A Lei $\mathrm{n}^{\circ}$ 11.079/2004 enfatiza a necessidade de se indicarem objetivos viáveis, que permitam a identificação de fontes de informação e de condições instrumentais favoráveis ao estabelecimento de parcerias público-privadas, conforme dispõe o art. $4^{\circ}$ da citada lei:

I - eficiência no cumprimento das missões de Estado
e no emprego dos recursos da sociedade;
II - respeito aos interesses e direitos dos
destinatários dos serviços e dos entes privados
incumbidos da sua execução;
III - indelegabilidade das funções de regulação
jurisdicional do exercício do poder de polícia e de
outras atividades exclusivas do Estado;
IV - responsabilidade fiscal na celebração e
execução das parcerias;
V- transparência dos procedimentos e das decisões;
VI - repartição objetiva de riscos entre as partes;
VII - sustentabilidade financeira e vantagens
socioeconômicas dos projetos de parceria. ${ }^{17}$

O próprio escopo das diretrizes personifica a ideia de que seja possível, ao mesmo tempo, garantir melhores resultados em contratação pública; atender às necessidades da sociedade em serviços públicos; assegurar o equilíbrio das contas públicas; manter a tutela das garantias fundamentais inerentes aos destinatários e aos entes privados; utilizar mecanismos empresarias e gerir a coisa pública; prover a sustentabilidade do negócio numa versão sustentável.

\footnotetext{
${ }^{17}$ BRASIL. Lei $\mathrm{n}^{\mathrm{o}}$ 11.079, de 30 de dezembro de 2004. Institui normas gerais para licitação e contratação de parceria público-privada no âmbito da administração pública. Diário Oficial da União. Brasília, 30 de dezembro
}

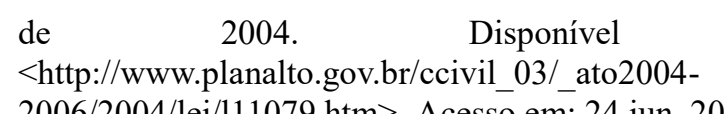
2006/2004/lei/111079.htm>. Acesso em: 24 jun. 2016. 
A integração desses elementos constitui um alcance complexo de resultados a serem efetivados através de um contrato administrativo, ou seja, encaminha em direção a uma incompletude contratual. No entanto, as diretrizes dispostas na Lei das PPPs demonstram uma série de exigências desnecessárias, visto que a função de governar jamais poderia ser delegada a iniciativa privada.

\subsection{Eficiência}

O princípio da eficiência estabelece uma relação entre os meios (aplicação) e os resultados das parcerias público-privadas. Efetiva-se com o procedimento de manifestação de interesse ou do projeto de análise do custo-benefício ou custoeficácia, os quais podem assumir duas vertentes: a) fixar o nível de custo e maximizar os benefícios; b) fixar o nível de benefícios e minimizar os custos. Essas dimensões são analisadas sob uma perspectiva racional de escolha pública. Levam em consideração aspectos políticos, financeiros, administrativos, sociais e ideológicos, presentes em âmbito nacional ou internacional. ${ }^{18}$

Segundo Bruno Salama ${ }^{19}$, o princípio da eficiência diz respeito "à maximização de ganhos e minimização de custos". Configura uma correlação entre os meios jurídicos e os fins normativos que trazem implicações para a própria legitimidade do direito. Essa conexão permite argumentar que as diretrizes para contratação de parcerias público-privadas baseiam-se na

\footnotetext{
${ }^{18}$ URIO, Paolo. Public-private partnerships success and failures factors for in-transition countries. New York: University Press of America, 2010. p. 29-30.

19 SALAMA, Bruno. O que é "direito e economia"? Selected Works of Bruno Meyerhof Salama: Contribution to books, 2008. Disponível em: <http://works.bepress.com/bruno_meyerhof_salama/docty pe.html>. Acesso em: 06 ago. 2016.

${ }^{20}$ BRASIL. Lei Complementar $n^{\circ} 101$, de 4 de maio de 2000. Estabelece normas de finanças públicas voltadas para a responsabilidade na gestão fiscal e dá outras providências.
}

eficiência e no emprego de recursos, através de financiamento privado. Culminam em melhorias no bem-estar dos consumidores.

\subsection{Responsabilidade fiscal e transparência}

A ideia de equilíbrio fiscal veio a ser sedimentada com o advento da Lei Complementar $\mathrm{n}^{\mathrm{o}} 101$, de 4 de maio de $2000^{20}$, conhecida como Lei de Responsabilidade Fiscal. Estabeleceu regras codificadas para a implantação de uma gestão fiscal no âmbito da administração pública brasileira. A citada lei possui quatro princípios básicos em sua estrutura: a) planejamento; b) equilíbrio das contas públicas, com a limitação da dívida pública compatível com a receita e o patrimônio público; c) preservação do patrimônio público; d) transparência dos demonstrativos orçamentários e contábeis.

No Brasil, o ajuste fiscal, iniciado na década de 1990, consubstanciando-se com o advento da Lei de Responsabilidade Fiscal, contribuiu para estabelecer o relacionamento entre orçamento e realidade. Seu principal propósito foi fortalecer as instituições para fazer investimentos objetivando o equilíbrio fiscal ${ }^{21}$ e, consequentemente, estabilizando as finanças públicas.

A esfera legislativa das parcerias públicoprivadas considera alguns dispositivos referentes aos limites prudenciais previstos na Lei de Responsabilidade Fiscal. Isso se deve à vinculação da contraprestação pecuniária do parceiro público ao parceiro privado, tanto nos casos de concessão patrocinada como de

Diário Oficial da União. Brasília, 4 de maio de 2000. Disponível

em: <http://www.planalto.gov.br/ccivil_03/leis/lcp/lcp101.htm $>$. Acesso em: 22 jul. 2016.

21 PEREIRA, Maria Marconiete Fernandes. Parceria público-privada: a superação da dicotomia público-privado na relação contratual, quando da repartição do risco e da conformação da responsabilidade fiscal. 2009. $167 \mathrm{f}$. Dissertação (Mestrado em Ciências Jurídicas)Universidade Federal da Paraíba, João Pessoa, 2009. 
concessão administrativa, quando envolver adicionalmente a cobrança de tarifa dos usuários e da administração pública. Nesse caso, há um reflexo direto no comprometimento da receita corrente líquida. A lei que disciplina as parcerias público-privadas estabelece um comando limitador de gastos aos Estados, Distrito Federal e Municípios, quanto ao comprometimento da dívida pública, com a finalidade de manter a rigidez do controle fiscal.

A LRF tem o escopo de sedimentar o regime de gestão fiscal responsável, mediante a implementação de mecanismos legais que devem nortear os rumos da administração pública. Constitui um código de conduta gerencial a ser observado na condução da coisa pública. Esse diploma legal traça limites, estabelece controle e oferece elementos balizadores para os gastos públicos, disciplinando o fluxo de recursos financeiros necessários à sua efetiva realização. ${ }^{22}$

\subsection{Repartição objetiva de riscos}

A repartição dos riscos desencadeia um sistema bilateral de segurança jurídica contratual. Segundo Fernando Araújo ${ }^{23}$, a partilha dos riscos entre as partes configura um dos objetivos mais relevantes dos contratos, visto que, no seu âmago, insere-se o consenso da relação contratual. Ao estabelecer, em dispositivo legal, a repartição objetiva dos riscos, cria-se a necessidade de mensurá-los, de modo a avaliar suas consequências, não sendo um fim em si mesmo. A identificação dos riscos em projetos de parcerias público-privadas tem a capacidade de identificar parceiros e geri-los, uma vez que "a natureza do risco, a arte e a ciência da escolha

\footnotetext{
22 NASCIMENTO, Carlos Valder de. Comentários aos $\operatorname{artigos} 1^{\circ}$ a 17 da Lei de Responsabilidade Fiscal. In: MARTINS, Ives Gandra da Silva; NASCIMENTO, Carlos Valder do (Org.). Comentários à Lei de Responsabilidade Fiscal. 2. ed. São Paulo: Saraiva, 2007. p. 11.

23 ARAÚJO, Fernando. Teoria económica do contrato. Coimbra: Almedina, 2007.
}

estão no cerne de nossa economia moderna de mercado". ${ }^{24}$

No ordenamento jurídico brasileiro, a repartição de riscos em contratos públicos é uma inovação. Nas relações contratuais privatistas, essa cláusula é conhecida e tratada pela doutrina como possível e justa. Somente a partir dos anos de 1990, implantou-se um sistema de risco partilhado nos contratos com a administração pública, nos casos de contratos previstos na Lei ${ }^{\circ}$ 8.666/93, e também na Lei $n^{\circ} 8.987 / 93$. Celso Antonio Bandeira de Mello ${ }^{25}$ chama a atenção para a álea extraordinária ou fato do príncipe, quanto o causador da imprevisão é o próprio Estado. Portanto, não seria razoável que o parceiro privado fosse o único responsável pelos prejuízos daí decorrentes, ou seja, suportasse o ônus de uma omissão estatal.

$\mathrm{O}$ instrumento contratual vincula os entes públicos e os particulares a procedimentos voltados à atividade econômica, acompanhado por uma base_consensual, haja vista que as duas partes optam bilateralmente por repartir os riscos, convertendo-a numa relação jurídica pública. As incertezas e as probabilidades devem ser consideradas na construção da matriz de riscos. As partes devem avaliar as variáveis econômicas e outros aspectos específicos próprios de cada contrato, ajustando aquilo que melhor atue nos negócios. Além disso, devem abster-se da visão do setor privado, sendo eficientes em suas atuações, com base em um desejável elemento de flexibilização. ${ }^{26}$

Por conseguinte, a necessidade de repartir os riscos em contratos públicos, especialmente, nas parcerias público-privadas, confere solidez aos negócios. Sua continuidade depende dos

\footnotetext{
${ }^{24}$ AVEN, Terje. Foundations of risk analysis. A knowledge and decision-oriented perspective. England: John Wiley \& Sons, 2003. p. 1-2.

${ }^{25}$ MELLO, Celso Antônio Bandeira de. Curso de direito administrativo. 25. ed. São Paulo: Malheiros, 2008.

${ }^{26}$ ARAÚJO, Fernando. Teoria económica do contrato. Coimbra: Almedina, 2007.
} 
fatores negociados, nos quais poderão incidir elementos negativos, gerando prejuízos, ou elementos positivos, resultando no equilíbrio das partes. Assim, os critérios referentes aos resultados deverão estar inseridos no contexto socioeconômico, conforme as metas anteriormente estipuladas para cada área.

\subsection{Sustentabilidade}

O conceito de sustentabilidade ganhou notoriedade, quando passou a ser vinculado à preservação do meio ambiente, como um dos fatores necessários à continuidade da civilização humana. Em resposta, a sociedade está ligada aos problemas ambientais, podendo escolher entre preservar ou destruir a natureza. ${ }^{27} \mathrm{Da}$ primeira opção nasce a concepção de desenvolvimento sustentável. Essa ideia liga-se ao entendimento de desenvolvimento sustentável adotada pelo Relatório de Brundtland ${ }^{28}$, em 1987. Nele, defende-se um desenvolvimento que satisfaça às necessidades da presente geração, mas sem comprometer as gerações futuras.

O conceito de sustentabilidade expressa uma mensagem ordenadora do sistema socioeconômico, manifestada pela Lei das Parcerias, direcionando para além das fronteiras a importância dos fatores ambientais. Essa nova concepção busca conferir um peso maior nos contratos em relação aos métodos convencionais. Ela leva em consideração o interesse das futuras gerações, ao incorporar os fatores sociais, econômicos e institucionais, bem como os valores culturais da sociedade. ${ }^{29}$ Nesse sentido, a sustentabilidade financeira $e$ as vantagens socioeconômicas constituem uma das diretrizes para a contratação de parcerias público- privadas,

\footnotetext{
${ }^{27}$ BOSSELMANN, Klaus. The principle of sustainability: transforming law and governance. England: Ashgate, 2008. p. 11-13.

28 WORLD COMISSION ON ENVIRONMENT AND DEVELOPMENT. Our Common Future, "Brundtland Report”. New York: Oxford University Press, 1987.
}

conforme dispõe o art. $4^{\circ}$, inciso VII, da Lei $\mathrm{n}^{\circ}$ 11.079/2004.

A sustentabilidade econômica refere-se à atividade produtiva, identificando os custos e benefícios diretos ou indiretos que recaem sobre o empreendimento. Os principais fatores a serem considerados são a economicidade e a regulação necessária do mercado, permitindo a eficiência e consequente eficácia dos contratos. ${ }^{30}$

A sustentabilidade social vincula-se à materialização de direitos fundamentais. Considera a participação da sociedade como um aspecto relevante na busca de melhorias na qualidade de vida. Observa-se também na sustentabilidade a indicação de novos contornos de atuação da administração pública. Esta necessita adotar uma percepção imediata e apropriada, assumindo posição firme, diante dos impactos que podem ser causados pela contratação de parcerias público-privadas, tendo em vista que podem se estender pelo prazo de trinta anos.

A concepção subjacente de sustentabilidade, no caso de parcerias públicoprivadas, deve contemplar os seguintes aspectos:

- Melhoria na qualidade do projeto, em termos de custos versus benefícios;

- Atendimento proporcional às necessidades dos usuários, independentemente de seu poder aquisitivo;

- Melhoria na qualidade de vida da população;

- Impacto mínimo, em termos ambientais.

\section{PROCEDIMENTO LICITATÓRIO}

${ }^{29}$ GRIMSEY, Darrin; LEWIS, Mervyn K. Public private partnerships. The worldwide revolution in infrastructure provision and project finance. Northampton, MA, USA: Edward Elgar, 2004. p. 221.

${ }^{30}$ FREITAS, Juarez. Sustentabilidade: direito ao futuro. 2. ed. Belo Horizonte: Fórum, 2012. p. 65-67. 
A licitação está respaldada por princípios asseguradores da isonomia entre os concorrentes, visando à proposta mais vantajosa para a administração pública, além de promover o desenvolvimento sustentável. Deve observar os princípios da legalidade, impessoalidade, moralidade, igualdade, publicidade, probidade administrativa e economicidade, entre outros. Diante da imperatividade constitucional da licitação, afasta-se a concessão por privilégios, no julgamento das propostas dos licitantes.

O regramento constitucional estabelece que, entre as espécies de concessão, existe a necessidade de adotar-se o procedimento licitatório, na modalidade de concorrência. No conteúdo da licitação, justifica-se a conveniência da outorga e especifica-se o objeto a ser licitado, informando área e prazo, conforme exigência contida na Lei $\mathrm{n}^{\mathrm{o}} 11.079 / 2004$. Para fins de cumprimento desse normativo constitucional, as regras devem ser elaboradas de forma objetiva, sem dirigismo, com o intuito de obter a proposta mais vantajosa.

O procedimento licitatório indica a caracterização de atos sequenciais regrados pela legislação. Uma vez exaurida uma fase, dá-se seguimento à outra, precluindo a anterior. Segundo Marçal Justen Filho, "a figura do procedimento gera uma concepção horizontal para o fundamento de validade dos atos jurídicos". 31

Embora a Lei das Parcerias PúblicoPrivadas traga inovações dos tipos concessionários, não renova em termos de licitação, já que adota a concorrência, mesmo diante da complexidade dos interesses e dos riscos envolvidos, além da dimensão do objeto a contratar. A administração pública necessita entender que a futura contratação é um

\footnotetext{
${ }^{31}$ JUSTEN FILHO, Marçal. Teoria geral das concessões de serviço público. São Paulo: Dialética, 2003. p. 194.

32 JUSTEN FILHO, Marçal. Comentários à Lei de Licitações e Contratos Administrativos. 13.ed. São Paulo: Dialética, 2009.
}

instrumento de políticas públicas no âmbito econômico e social. É também um mecanismo de fomento a atividades consideradas socialmente desejáveis de intervenção. ${ }^{32}$

É imprescindível que a licitação promova valores imbuídos de interesse público tanto na fase interna como na fase externa. As fases interagem no âmbito do planejamento governamental, compatíveis com o Plano Plurianual (PPA) e as diretrizes institucionais das PPP.

\subsection{Fase interna}

A fase interna ou preparatória na licitação abrange a elaboração de todos os atos necessários ao instrumento convocatório, isto é, o edital. A Lei $\mathrm{n}^{\circ} 11.079 / 2004$ instituiu essa fase com exigências capazes de consolidar a eficiência e os resultados na prestação de serviços públicos. Segundo Marçal Justen Filho ${ }^{33}$, a fase interna apresenta relevância jurídica significativa, uma vez que a fixação das regras pertinentes ao processo licitatório depende do desenvolvimento satisfatório alcançado nessa fase. A inovação surge na fase interna, ao admitir que a iniciativa para a elaboração do projeto e, possivelmente, a contratação seja da administração pública ou da empresa privada. No entanto, quando o procedimento da fase interna dá-se por iniciativa da administração pública, não houve inovações, mantendo-se o procedimento já previsto em outros normativos licitatórios. Sobre a matéria, dispõe o art. 10 da Lei ${ }^{\circ}$ 11.079/04:

Art. 10. A contratação de parceria público-privada será precedida de licitação na modalidade de concorrência, estando a abertura do processo licitatório condicionada a:

33 JUSTEN FILHO, Marçal. Teoria geral das concessões de serviço público. São Paulo: Dialética, 2003. 
I - autorização da autoridade competente, fundamentada em estudo técnico que demonstre;

a) a conveniência e a oportunidade da contratação, mediante identificação das razões que justifiquem a opção pela forma de parceria públicoprivada;

b) que as despesas criadas ou aumentadas não afetarão as metas de resultados fiscais previstas no Anexo referido no $\S 1^{\circ}$ do art. $4^{\circ}$ da Lei Complementar $\mathrm{n}^{0} 101$, de 4 de maio de 2000, devendo seus efeitos financeiros, nos períodos seguintes, ser compensados pelo aumento permanente de receita ou pela redução permanente de despesa; e

c) quando for o caso, conforme as normas editadas na forma do art. 25 desta Lei, a observância dos limites e condições decorrentes da aplicação dos arts. 29, 30 e 32, da Lei Complementar $n^{\circ} 101$, de 4 de maio de 2000, pelas obrigações contraídas pela Administração Pública relativas ao objeto do contrato;

II - elaboração de estimativa do impacto orçamentário-financeiro, nos exercícios em que deva vigorar o contrato de parceria público-privada;

III - declaração do ordenador da despesa de que as obrigações contraídas pela Administração Pública, no decorrer do contrato, são compatíveis com a lei de diretrizes orçamentárias e estão previstas na lei orçamentária anual;

IV - estimativa do fluxo de recursos públicos suficientes para o cumprimento, durante a vigência do contrato e por exercício financeiro, das obrigações contraídas pela Administração Pública;

$\mathrm{V}$ - seu objeto deve estar previsto no plano plurianual em vigor no âmbito onde o contrato será celebrado. $^{34}$

A fase interna por iniciativa de empresa privada tem início com o procedimento de manifestação de interesse (PMI), já previsto na Lei de Concessão Comum (Lei nº 8.985/1995), que dispõe:

Art. 21. Os estudos, investigações, levantamentos, projetos, obras e despesas ou investimentos já

\footnotetext{
${ }^{34}$ BRASIL. Lei $\mathrm{n}^{\mathrm{o}}$ 8.987, de 13 de fevereiro de 1995. Dispõe sobre o regime de concessão e permissão da prestação de serviços públicos, previsto no art. 175 da Constituição Federal e dá outras providências. Diário Oficial da União. Brasília, 13 de fevereiro de 1995. Disponível em:

<http://www.planalto.gov.br/ccivil_03/leis/18987cons.htm >. Acesso em: 22 jun. 2016.

${ }^{35}$ Ibid.

${ }^{36}$ BRASIL. Decreto Federal no 5.977, de $1^{\circ}$ de dezembro de 2006. Regulamenta o art. $3^{\circ}$, caput e $\S 1^{\circ}$, da Lei n ${ }^{\circ} 11.079$,
}

efetuados, vinculados à concessão, de utilidade para a licitação, realizados pelo poder concedente ou com a sua autorização, estarão à disposição dos interessados, devendo o vencedor da licitação ressarcir os dispêndios correspondentes no edital. ${ }^{35}$

Essa regra foi corroborada pela Lei $\mathrm{n}^{\circ}$ 11.079/2004, pela Lei de Parceria PúblicoPrivada, bem como pelas concessões administrativas e patrocinadas. Cabe ressaltar que o procedimento de manifestação de interesse possui algumas peculiaridades, tais como: a) não gera nenhuma obrigação futura de licitação e contratação; b) não tem exclusividade; c) não confere direito de preferência para a outorga da concessão; d) não cria, por si só, qualquer direito ao ressarcimento dos valores envolvidos na sua elaboração; e) tem forma pessoal e intransferível. ${ }^{36}$

As normas definidoras do PMI não detalham o procedimento a ser adotado no julgamento das propostas ofertadas pela iniciativa privada. Todavia, extraem algumas diretrizes de atuação da administração pública, destacando-se as seguintes:

- Atendimento ao princípio da publicidade dos estudos;

- Delimitação da necessidade pública;

- Liberdade técnica à iniciativa privada;

- Estipulação de valor máximo de 2,5\% do total estimado dos investimentos necessários à implementação da respectiva parceria público-privada, para eventual ressarcimento dos projetos;

- Indicação do prazo máximo para a apresentação dos projetos, estudos,

de 30 de dezembro de 2004, que dispõe sobre a aplicação às parcerias público-privadas do art. 21 da Lei no 8.987 , de 13 de fevereiro de 1995, e do art. 31 da Lei $\mathrm{n}^{\circ}$ 9.074, de 7 de julho de 1995, para apresentação de projetos, estudos, levantamentos ou investigações, a serem utilizados em modelagens de parcerias público-privadas, no âmbito da administração pública federal, e dá outras providências. Diário Oficial da União. Brasília, $1^{\circ}$ de dezembro de 2006. Disponível em:

$<$ http://www.planalto.gov.br/ccivil_03/_ato2004-

2006/2006/Decreto/D5977.htm>. Acesso em: 23 jul. 2016. 
levantamentos ou investigações, de acordo com a complexidade, as articulações e as licenças necessárias para sua implementação;

- Não exigência prévia de disponibilidade orçamentária.

Nessa fase, identifica-se a necessidade de que, na tomada de decisão, o próprio Estado e o setor empresarial devem estar em sintonia com o interesse público, com base em fundamentos técnicos e jurídicos. O objetivo do procedimento de manifestação de interesse consiste em orientar a participação empresarial na estrutura de projetos de parcerias público-privadas. Essa orientação é feita através de estudos técnicos, ambientais, econômicos, jurídicos ou de engenharia, visando ao desenvolvimento de projetos de interesse público. $^{37}$

Não se pode desconhecer a vantagem da proposta formulada pela via do PMI. Porém, evidencia-se uma racionalidade limitada da capacidade humana em configurar todas as previsões e probabilidades de eventos futuros que provavelmente não estarão postos no procedimento de manifestação realizado pelo setor privado.

\subsection{Fase externa}

A fase externa se inicia com a consulta pública, como forma de cumprimento ao princípio da transparência. Nessa fase, os pretendentes poderão se manifestar de maneira a colaborar com a administração pública. Convém lembrar que o edital ou instrumento convocatório será acompanhado da minuta do contrato. As propostas serão apresentadas com as fases de procedimento invertidas. Assim, apresenta-se, inicialmente, a etapa de qualificação de propostas

37 GUIMARÃES NETO, Mario Queiroz; BATISTA, Adrian Machado. Procedimento de manifestação de interesse (PMI): diálogos com a iniciativa privada. III Congresso Consad de Gestão Pública, 2010. Disponível em: e, posteriormente, a fase de habilitação para aqueles que lograram êxito na primeira etapa. A esse respeito, dispõe o art. 10, inciso VI, da Lei $n^{\circ}$ 11.079/04:

Art. 10. A contratação de parceria público-privada será precedida de licitação, na modalidade de concorrência, estando a abertura do processo licitatório condicionada a: [...]

VI - submissão da minuta de edital e de contrato à consulta pública, mediante publicação, na imprensa oficial, em jornais de grande circulação e por meio eletrônico, que deverá informar a justificativa para a contratação, a identificação do objeto, o prazo de duração do contrato, valor estimado, fixando-se prazo mínimo de 30 (trinta) dias para recebimento de sugestões, cujo termo dar-se-á pelo menos 7 (sete) dias antes da data prevista para a publicação do edital.

\section{CONCLUSÃO}

O chamamento do setor privado para a colaboração na prestação de serviços públicos estruturantes deve agregar benefícios que justifiquem sua participação. Não basta a existência de disposições legais para que efetivamente ocorra a integração público-privada. Deve-se, no entanto, observar que o desempenho econômico não poderá ser o único critério a ser avaliado para se indicar a necessidade de convocar a iniciativa privada para implementação de parcerias público-privadas. Outros critérios devem ser considerados nesse engajamento. Um deles é a missão do Estado em atender às demandas da sociedade. Cabe-lhe promover o acesso da população aos serviços públicos, de forma igualitária e economicamente viável, sem deslocar, desnecessariamente, os recursos para o empreendimento empresarial.

Como foi visto, o Brasil possui uma legislação específica para as concessões. As modalidades de parcerias público-privadas são

<http://www.escoladegoverno.pr.gov.br/arquivos/File/Mat erial_\%20CONSAD/paineis_III_congresso_consad/painel _44/procedimento_de_manifestacao_de_interesse_dialogo s_com_a_iniciativa_privada.pdf $>$. Acesso em: 19 jun. 2016 . 
modeladas com tipologias especiais, isto é, promover as principais necessidades coletivas. administrativa e patrocinada, com o intuito de diferenciá-las das concessões comuns. Contudo, as identificações com outros institutos jurídicos foram mantidas na ordem jurídica brasileira. É o que acontece com a concessão administrativa que somente se diferencia do contrato de serviços continuados em razão do lapso temporal e do valor da contratação.

Por fim, os requisitos elencados na Lei $\mathrm{n}^{\circ}$ 11.079/2004 poderão indicar o caminho a ser trilhada pelas políticas públicas. Elas deverão

Além disso, devem contribuir para uma maior amplitude da capacidade institucional de implementação das parcerias público-privadas. Esse novo modelo de contratação conduzirá a um direcionamento comportamental capaz de assegurar objetivos de um novo ciclo de gestão pública em harmonia com as reais necessidades da população. Por fim, essas parcerias deverão assumir o compromisso de garantir às futuras gerações a adequada prestação de serviços públicos.

\section{REFERÊNCIAS}

ARAÚJO, Fernando. Teoria económica do contrato. Coimbra: Almedina, 2007.

AVEN, Terje. Foundations of risk analysis. A knowledge and decision-oriented perspective. England: John Wiley \& Sons, 2003.

BOSSELMANN, Klaus. The principle of sustainability: Transforming Law and Governance. England: Ashgate, 2008.

BRASIL. Constituição da República Federativa do Brasil de 1988. Diário Oficial da União, Brasília, 5 de outubro de $1988 . \quad$ Disponível em: <http://www.planalto.gov.br/ccivil_03/constituicao/constituicaocompilado.htm>. Acesso em: 22 jun. 2016.

Decreto Federal $\mathrm{n}^{\mathrm{o}}$ 5.977, de $1^{\mathrm{o}}$ de dezembro de 2006. Regulamenta o art. $3^{\circ}$, caput e $\S 1^{\circ}$, da Lei $n^{\circ} 11.079$, de 30 de dezembro de 2004 , que dispõe sobre a aplicação às parcerias público-privadas do art. 21 da Lei no 8.987, de 13 de fevereiro de 1995, e do art. 31 da Lei $\mathrm{n}^{\circ} 9.074$, de 7 de julho de 1995, para apresentação de projetos, estudos, levantamentos ou investigações, a serem utilizados em modelagens de parcerias público-privadas, no âmbito da administração pública federal, e dá outras providências. Diário Oficial da União. Brasília, $1^{\circ}$ de dezembro de 2006. Disponível em: <http://www.planalto.gov.br/ccivil_03/_ato20042006/2006/Decreto/D5977.htm>. Acesso em: 23 jul. 2016.

. Lei Complementar $n^{\circ} 101$, de 4 de maio de 2000. Estabelece normas de finanças públicas voltadas para a responsabilidade na gestão fiscal e dá outras providências. Diário Oficial da União. Brasília, 4 de maio de 2000.2 Disponível em: <http://www.planalto.gov.br/ccivil_03/leis/lcp/lcp101.htm>. Acesso em: 22 jul. 2016.

. Lei n ${ }^{\circ} 8.987$, de 13 de fevereiro de 1995. Dispõe sobre o regime de concessão e permissão da prestação de serviços públicos, previsto no art. 175 da Constituição Federal e dá outras providências. Diário Oficial da União. Brasília, 13 de fevereiro de 1995. Disponível em: <http://www.planalto.gov.br/ccivil_03/leis/18987cons.htm>. Acesso em: 22 jun. 2016. 
. Lei n ${ }^{\circ} 11.079$, de 30 de dezembro de 2004. Institui normas gerais para licitação e contratação de parceria público-privada no âmbito da administração pública. Diário Oficial da União. Brasília, 30 de dezembro de 2004. Disponível em: <http://www.planalto.gov.br/ccivil_03/_ato20042006/2004/lei/111079.htm>. Acesso em: 24 jun. 2016.

CALDERÓN, César; SERVÉN, Luis. The effects of infrastructure development on growth and income distribution. In: Reunión Latinoamericana sobre el Financiamiento de la Infraestructure, April 15-16, 2004, Buenos Aires. Publications... Washington, DC: WBG, 2004.

CAVALLO, Domingo. Latin America and The Washington Consensus. Harvard University Economics Department. Spring, 2004. Disponível em: <http://www.cavallo.com.ar/wpcontent/uploads/2011/08/LA-and-the-Washington-Consensus.pdf>. Acesso em: 22 abr. 2017.

DANTAS, Ivo. Teoria do Estado contemporâneo. Rio de Janeiro: Forense, 2008.

DI PIETRO, Maria Sylvia Zanella. Parcerias na administração pública: concessão, permissão, franquia, terceirização, parceria público-privada e outras formas. 9. ed. São Paulo: Atlas, 2012.

DINIZ, Eli. O pós-Consenso de Washington: globalização, Estado e governabilidade reexaminados. In (Org.). Globalização, Estado e desenvolvimento: dilemas do Brasil no novo milênio. Rio de Janeiro: FGV, 2007.

EVANS, Peter B. Análise do Estado no mundo neoliberal: uma abordagem institucional comparativa. Revista de Economia Contemporânea, Rio de Janeiro, n. 4, jul./dez. 1998.

FREITAS, Juarez. Sustentabilidade: direito ao futuro. 2. ed. Belo Horizonte: Fórum, 2012.

GRIMSEY, Darrin; LEWIS, Mervyn K. Public private partnerships. The worldwide revolution in infrastructure provision and project finance. Northampton, MA, USA: Edward Elgar, 2004.

GUIMARÃES NETO, Mario Queiroz; BATISTA, Adrian Machado. Procedimento de manifestação de interesse (PMI): diálogos com a iniciativa privada. III Congresso Consad de Gestão Pública, 2010. Disponível em:

<http://www.escoladegoverno.pr.gov.br/arquivos/File/Material_\%20CONSAD/paineis_III_congress o_consad/painel_44/procedimento_de_manifestacao_de_interesse_dialogos_com_a_iniciativa_priva da.pdf>. Acesso em: 19 jun. 2016.

JUSTEN FILHO, Marçal. Teoria geral das concessões de serviço público. São Paulo: Dialética, 2003. 2009. Comentários à Lei de Licitações e Contratos Administrativos. 13. ed. São Paulo: Dialética,

KETTL, Donald F. Global reinvention: basic issues, questions ahead. Forum on Reinventing Government. Jan. 1999. Disponível em:

<http://www.brookings.edu/research/papers/1999/01/14governance-kettl>. Acesso em: 26 jul. 2016.

MELLO, Celso Antônio Bandeira de. Curso de direito administrativo. 25. ed. São Paulo: Malheiros, 2008. 
NASCIMENTO, Carlos Valder de. Comentários aos artigos $1^{\circ}$ a 17 da Lei de Responsabilidade Fiscal. In: MARTINS, Ives Gandra da Silva; NASCIMENTO, Carlos Valder do (Org.). Comentários à Lei de Responsabilidade Fiscal. 2. ed. São Paulo: Saraiva, 2007.

OLIVEIRA, Gustavo Henrique Justino de. Estado contratual, direito ao desenvolvimento e parceria público-privada. In: TALAMINI, Eduardo; JUSTEN, Monica Spezia (Org.). Parcerias públicoprivadas: um enfoque multidisciplinar. São Paulo: Revista dos Tribunais, 2005.

PEREIRA, Maria Marconiete Fernandes. Parceria público-privada: a superação da dicotomia públicoprivado na relação contratual, quando da repartição do risco e da conformação da responsabilidade fiscal. 2009. 167 f. Dissertação (Mestrado em Ciências Jurídicas)-Universidade Federal da Paraíba, João Pessoa, 2009.

RIGOLON, Francisco José Zagari; PICCININI, Maurício Serrão. O investimento em infraestrutura e a retomada do crescimento econômico sustentado. Textos para Discussão do BNDES, Texto para Discussão $\mathrm{n}^{\mathrm{o}}$ 63, Rio de Janeiro, IPEA, dez. 1997. Disponível em: <http://www.bndes.gov.br/SiteBNDES/export/sites/default/bndes_pt/Galerias/Arquivos/conheciment o/td/Td-63.pdf>. Acesso em: 28 jun. 2016.

SALAMA, Bruno. O que é "direito e economia"? Selected Works of Bruno Meyerhof Salama: Contribution to books, 2008. Disponível em: <http://works.bepress.com/bruno_meyerhof_salama/doctype.html>. Acesso em: 06 ago. 2016.

SCHIMIDT-HEBBEL, Klaus; SERVÉN, Luís; SOLIMANO, Andrés. Saving investment: paradigmas, puzzles, policies. The World Bank Research Observer, v. 11, n. 1, fev. 1996.

UGÁ, Maria Alícia Dominguez. Ajuste estrutural, governabilidade e democracia. In: GERSCHMAN, Silvia; VIANNA, Maria Lucia Werneck. A miragem da pós-modernidade e políticas sociais no contexto da globalização. Rio de Janeiro: Fiocruz, 1997.

URIO, Paolo. Public-private partnerships success and failures factors for in-transition countries. New York: University Press of America, 2010.

WORLD BANK. World Development Report 1994: infrastructure for development (Executive Summary). Washington, DC, 1994. Disponível em: <http://wwwwds.worldbank.org/external/default/WDSContentServer/IW3P/IB/2007/10/10/000011823_20071010 172019/Rendered/PDF/13483.pdf>. Acesso em: 30 jun. 2016.

WORLD COMISSION ON ENVIRONMENT AND DEVELOPMENT. Our Common Future, “Brundtland Report”. New York: Oxford University Press, 1987. 
